\title{
MODEL TEST AND NUMERICAL ANALYSIS METHODS IN TUNNEL EXCAVATION PROBLEM
}

\author{
YING CUI ${ }^{\text {i) }}$ and MaKoto KIMURA ${ }^{\text {ii) }}$
}

\begin{abstract}
Tunnels serve various functions such as in subway systems, underground electric power lines, gas pipes, telecommunication lines, water supplies and sewer lines and many other pipelines. The trend of tunnel construction is toward deeper and longer tunnels. In addition, the excavation of tunnels in difficult ground conditions is now not uncommon, though the tunnels themselves are still difficult to construct. Advanced studying methods have been developed for the prediction, monitoring and evaluation of the performance of tunnels and ground. Today, experimental methods and analytical methods are the main approaches used in tunnel studies. In this paper, the present state of tunnel construction and the main study methods are discussed, and the various experimental and analysis methods and their usage are compared. Tunnel excavation is very complex because it involves soils, structure and interaction problems. There is no one perfect studying method, though there are good combinations of numerical analyses and experimental methods which provide the optimum approach for solving tunnel related problems.
\end{abstract}

Key words: field measurements, numerical analysis, model test, tunnel (IGC: E14)

\section{INTRODUCTION}

Since seventy percent of Japan is topographically mountainous, tunnels have been built from one place to another in order to secure traffic paths for railways and roadways. In urban areas, in addition to subways, there is an extensive network of tunnel for lifelines such as sewerage, waterworks, etc. An enormous amount of attention is being given to the design of tunnels, the selection of the construction method, and the best auxiliary methods to be employed. Model tests and numerical analyses are the standard for prediction, monitoring and the evaluation of the performance of both tunnels and ground.

This paper includes an overview of the tunnel related problems published in the many editions of Soils and Foundations (S\&F) since it's foundation. Study methods, including experimental methods and numerical methods used in tunnel research, are also discussed.

\section{PREVIOUSLY PUBLISHED PAPERS IN S\&F}

Twenty papers focused on underground constructions including tunnels and pipelines have been published in $\mathrm{S} \& \mathrm{~F}$ during the 50 years since this journal came into being. Eighty percent of these papers (16 papers) were focused on tunnel related problems. As well as looking at the number of the papers in each ten year interval since the inception of the journal in the 1960s to date, the research objectives and method employed in each study will be outlined.

\section{Number of Published Manuscripts}

The following is a list of the relevant papers publishd in S\&F: Dufour et al., 2009; Sung et al., 2006; Shahin et al., 2004; Khoshnoudian and Shahrour, 2002; Lee et al., 2002; Longanthan et al., 2001; Goto et al., 1999; Hashimoto et al., 1999; Komiya et al., 1999; Sugiyama et al., 1999; Lee et al., 1999; Nakai et al., 1997; Sato, 1983; Yoshikoshi et al., 1978; Christian and Wong, 1973; Shiraishi, 1969.

Figure 1 shows the number of the papers published per decade from the 1960s to 2000s. The numbers listed in the bar chart shows the number of the papers published in the span of ten years. From the figure, it can be seen that there were two or less tunnel related papers published in

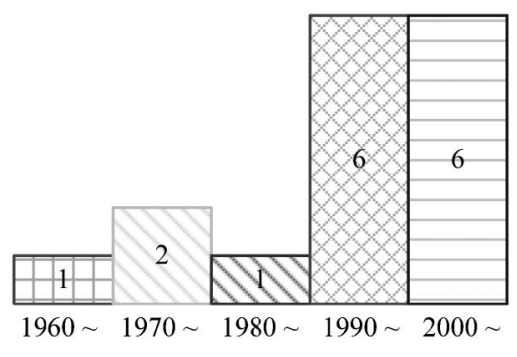

Fig. 1. Number of papers every 10 years

i) Department of Civil Engineering, Meijo University, Nagoya, Japan (cuiging@meijo-u.ac.jp).

ii) Department of Civil and Earth Resources Engineering, Kyoto University, Kyoto, Japan (kimura@icc.kyoto-u.ac.jp). The manuscript for this paper was received for review on October 8, 2010; approved on October 12, 2010. 


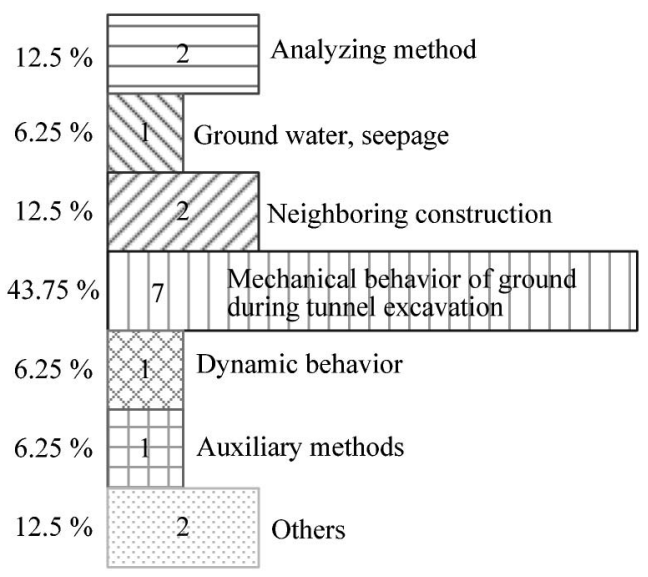

Fig. 2. Subjects of researches

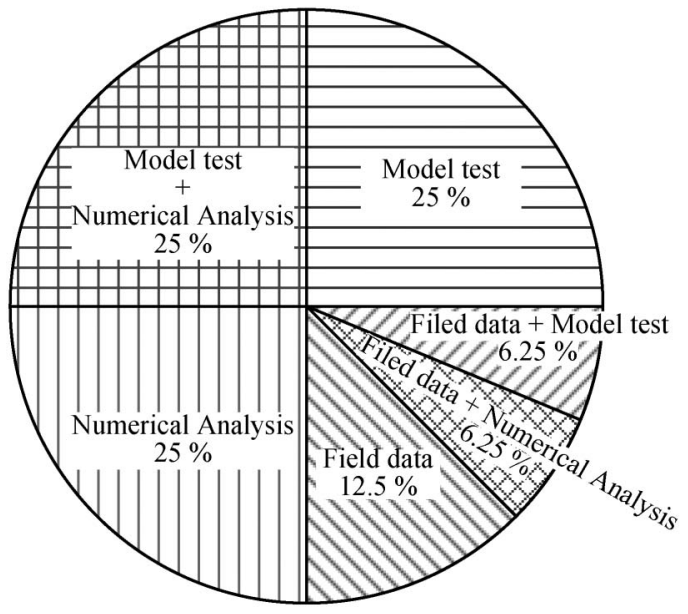

Fig. 3. Studying methods used in each paper

S\&F per decade in the first, second and third decade since the first publication of S\&F. In the 1990s and 2000s, the number of published papers increased to 6 papers. However, this number is still relatively low. The relatively low number of tunnel related publications in S\&F could probably be attributed to the existence of other journals which deals specifically with tunnels, for example the Journal of Tunnel Engineering (JSCE), the Proceedings of Tunnel Engineering (JSCE) and the international journal of Tunnelling and Underground Space Technology (ITA).

Figure 2 shows the total number of the papers in the last fifty years categorized by the research objectives. Half of the papers discussed the mechanical behavior of ground during tunnel excavation process. Compared with this, there is only one paper each dealing with the ground water problem, dynamic problem of ground and auxiliary methods, respectively.

\section{Methods of Study}

The papers are categorized according to the studying methods employed in Fig. 3. The most common studying methods used in the research included model tests, nu-

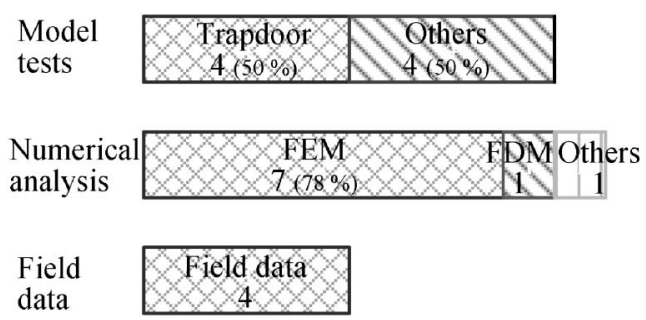

Fig. 4. Number of papers for each studying method

merical analysis and field data analysis. Model tests and numerical analysis were conducted in more than half of the papers and both model tests and numerical analyses were featured in $25 \%$ of the papers. Field data were analyzed in $25 \%$ of the papers, and half of them were combined with model tests or numerical analyses.

Figure 4 shows details of the studying methods used in these papers. From the figure, it can be seen that trapdoor is the most commonly used experiment apparatus and FEM is widely used for numerical analyses.

\section{PRESENT STATE OF THE TUNNELING}

\section{Deep Tunneling}

In large cities in Japan, such as Tokyo, Osaka, and Nagoya, shallow underground space is already congested with various underground structures like subways, electric power lines, gas pipes, telecommunication lines, water supplies and sewer lines as well as many other tunnels and pipelines. Therefore, the new tunnels are constructed deeper because they have to give a wide berth to the above-mentioned existing underground structures.

Cases of deep tunnel construction are increasing rapidly after the enactment of the new law called "The Special Measures Act for Public Use of Deep Underground Space" in Japan. This new law came into effect on April 1,2001 , and the main purpose of this law is to regulate the use of deep underground space in an appropriate and rational manner for public purpose.

Some typical examples in Japan, in which deep tunnels have been excavated, include a tunnel for high voltage electric power lines at a depth of $66 \mathrm{~m}$ in Osaka, a conduit for a gas pipeline at a depth of $60 \mathrm{~m}$ in Yokohama, and a sewer line tunnel at a depth of $57 \mathrm{~m}$ in Tokyo. Deep tunnels have also been excavated in the US: the New York water supply tunnel is a depth of $150 \mathrm{~m}$ and the Chicago TARP tunnel is at a depth of between 61 and $107 \mathrm{~m}$.

The latest examples of deep tunneling construction include the mega infrastructure project in Singapore called “Deep Tunnel Sewerage System”, (DTSS). The DTSS project was started in 1999 and the entire project will take over 20 years. The tunnel is expected to be about $38 \mathrm{~km}$ long, with a diameter ranging between 3.6 to $6.0 \mathrm{~m}$ and founded at a depth between 18 to $50 \mathrm{~m}$. Most of the tunnels will be bored by shield type TBMs. (PUB, Singapore's national water agency: http://www.pub.gov.sg/ dtss/Pages/default.aspx) 


\section{Large Cross Section Tunnels}

Recently, the construction of tunnels with large cross sections, with an excavated cross section area of about $130 \mathrm{~m}^{2}$, is increasing. Examples of such tunnels include tunnels with three-lane roads, roads with sidewalks, etc. An example of such a large cross section tunnel with an excavated cross section area ranging between $700-800 \mathrm{~m}^{2}$ has been under construction using the Multi-Micro Shield Tunneling method for a highway tunnel in Kawasaki, Japan. Also, a large world-class highway tunnel with a diameter of $12.84 \mathrm{~m}$ has been bored by TBM in Takayama, Japan.

The latest large tunnel construction in Japan using a shield machine is the Yamanote Tunnel between Takamatsu JCT and Nishishinjuku JCT on the Capital Expressway. The shield machine used for the construction of this tunnel opened to traffic on March 1, 2010, was about $12.5 \mathrm{~m}$ in diameter. (Technology of Metropolitan Expressway, Japan: http://www.tech-shutoko.jp). The latest large tunnel construction in Japan excavated by NATM is the Namikata national liquefied petroleum gas stockpiling base. Namikata base is an extra-large tunnel $30 \mathrm{~m}$ in height and $653 \mathrm{~m}^{2}$ in cross section area constructed $150 \mathrm{~m}$ from the ground surface. This tunnel is $430 \mathrm{~m}$ long and it will be used for stocking liquefied petroleum gas.

\section{Shallow Overburden Tunnel Excavation on Soft Ground Using NATM}

Up to now, the open-cut method is the main tunneling method for excavating shallow overburden tunnel on soft ground. Recently, due to the improvement of the construction techniques and the technical development of auxiliary methods, the construction of shallow overburden tunnel on soft ground using NATM (New Austrian Tunneling Method) have been on the increase. For example, during the route extension work of the Tohoku Shinkansen (Bullet line), in Japan, various types of shallow overburden tunnels were constructed (Kitagawa et al., 2005). However, ground subsidence frequently occurred as a result of the low stiffness of ground arising from soft ground and the incompletion of the arch effect due to the shallow overburden. Various kinds of auxiliary methods have therefore been utilized in the above fields to ensure safety during tunnel excavation and to prevent ground subsidence (Kitagawa et al., 2005).

\section{EXPERIMENTAL METHODS}

During the planning and design of a new untried construction with no clear criterion, trial constructions, field measurements and model tests are frequently carried out to check the mechanical behavior of ground and tunnels. Obtaining detailed information from the trial construction and field measurement is difficult due to time limitations and cost. Compared to the trial construction and field measurements, much information is made available by model tests, which can be easily conducted inexpensively. These provide rational approach to obtaining as much information of construction as possible, model tests having recently become one of the most popular studying methods.

\section{Real Excavation}

It is desirable to perfectly simulate the stress state in real construction and the real tunnel excavating process in model tests. Therefore, an experimental method that involves excavating the model ground has been frequently employed in research works.

Taguchi et al. (2003) carried out grouting tests to check the effect of a new pre-lining method. This method makes a reverse $\mathrm{T}$ type body using high pressure grouting with three direction nozzles. A $5 \mathrm{~m}$ high soil-cement embankment shown in Fig. 5 was constructed and tunnels were excavated using $0.4 \mathrm{~m}^{3}$ backhoe in this experiment. The tunnel was semi-circular shaped with a radius of $2.5 \mathrm{~m}$.

\section{Exerting a Forced Displacement}

(1) Trapdoor apparatus

The trapdoor apparatus (Terzaghi, 1936) is often used to predict the active (loosened) earth pressure on the tunnel lining and the support system. Also, Terzaghi's formula (1943) of the active earth pressure on the trapdoor is still often applied to the design of the tunnel support system. The tunneling process is simulated by lowering a supporting plate (the trapdoor) to reduce the confining stress in the localized area.

Dry sand was used to make the ground in Terzaghi's

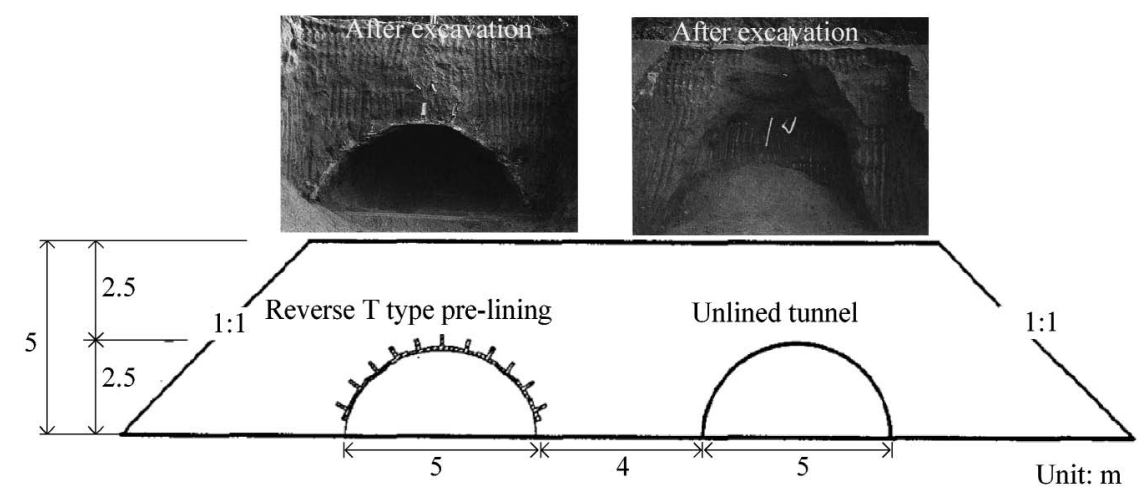

Fig. 5. Real excavation (Taguchi et al., 1993) 


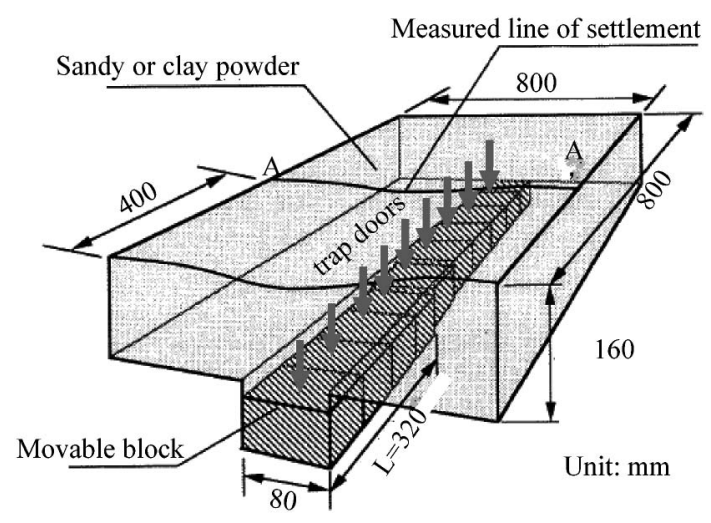

Fig. 6. Simulation of tunnel excavating process using 3D trapdoor apparatus (Nakai et al., 1997)

3D model test. Murayama and Matsuoka (1971) and Adachi et al. (1994) have developed a 2D trapdoor apparatus, with aluminum bars used to make the model ground.

Nakai et al. (1997) carried out 3D trapdoor model tests using a continuous trapdoor apparatus, as shown in Fig. 6 to investigate the $3 \mathrm{D}$ effect and dilatancy effect on the ground movements occurring during tunnel excavation. The apparatus consisted of 10 blocks of $80 \mathrm{~mm}$ in width which were set along the centerline of an iron table. These blocks could be moved upwards and downwards individually or simultaneously. Shahin et al. (2004) used the same trapdoor apparatus to investigate the mechanical behavior of ground during tunnel excavation. Both 2D and $3 \mathrm{D}$ trapdoor experiments were carried out by Sung et al. (2006) to investigate the surface settlements and earth pressure due to tunneling with and without an existing neighboring foundation structure. In addition, Cui et al. (2008) carried out a series of model tests using trapdoor apparatus to clarify the effect of the foot reinforcement side pile, which is one of the auxiliary methods. In all the above studies, the trapdoor was used. This shows the importance of the trapdoor in the tunnel studies.

(2) Pullout tests

A 3D trapdoor apparatus is mainly used to check the 3D effects of the ground during tunneling while a 2D trapdoor apparatus is mainly used to check the mechanical behavior of ground in the transverse direction of the tunnel. A pullout test was also developed to check the mechanical behavior of ground along the traveling direction of the tunnel.

Kirsch (2009) carried out small-scale pullout experiments to investigate the stability of the face during tunnel excavation. The experimental apparatus used in this research is as shown in Fig. 7. The tunnel was represented by a half-cylinder of perspex, with an inner diameter of $10 \mathrm{~cm}$ and a wall thickness of $4 \mathrm{~m}$. An aluminum piston was fitted into the tunnel to support the soil. The piston was mounted on a horizontal steel rod, which was supported by a one-dimensional roller bearing inside the side wall of the box. The looseness of the face of tunnel was modeled by pulling out the piston by turning the knob in

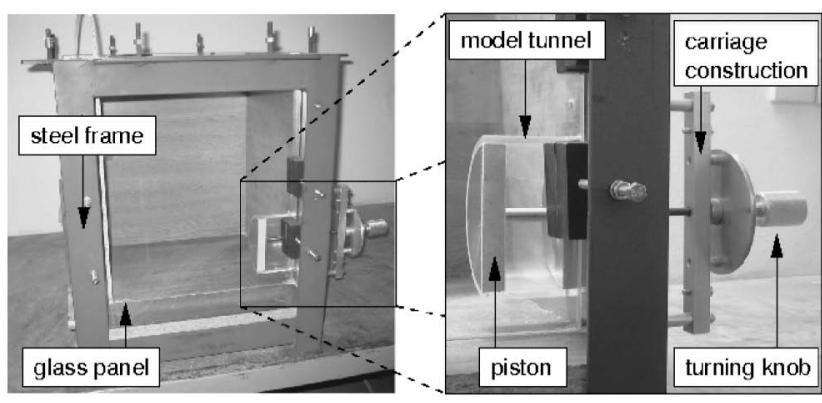

Fig. 7. Box and model tunnel (Kirsch, 2009)

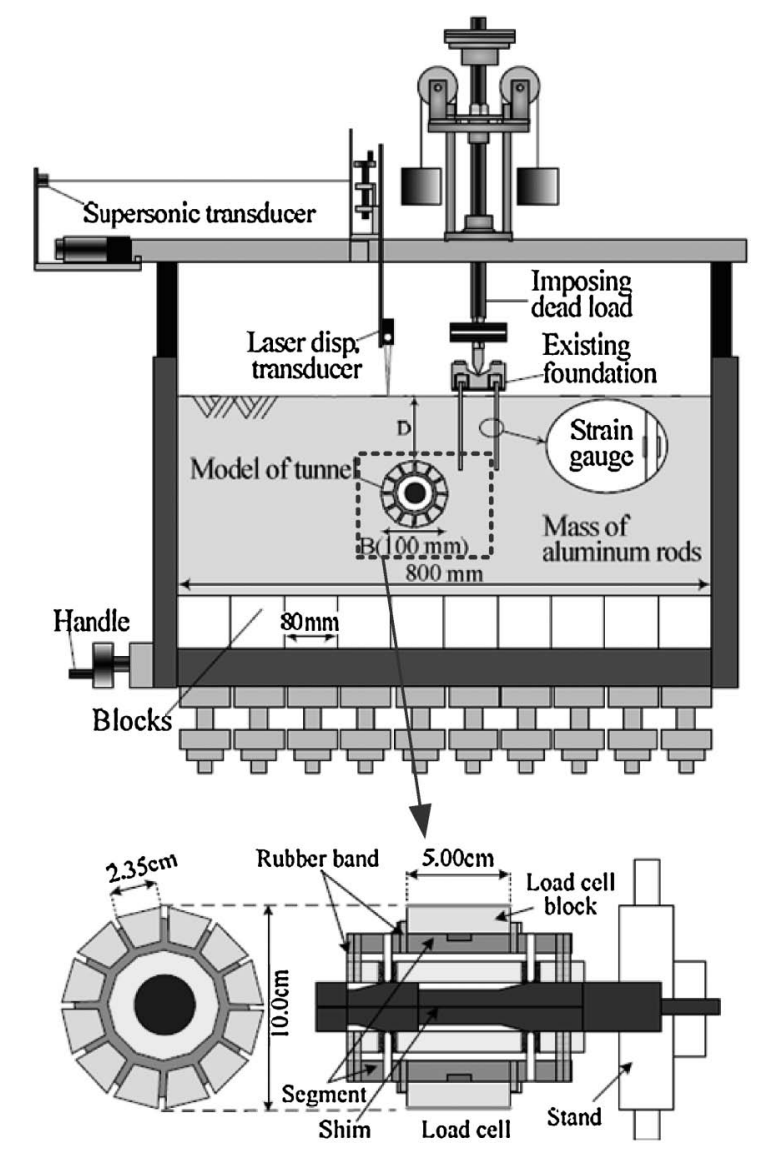

Fig. 8. 2D tunnel excavation modeling experimental apparatus (Kikumoto et al., 2009)

extension of the piston axis.

(3) Control of the dimension of tunnel lining

The deformation of the tunnel lining during tunnel excavation is difficult to simulate in both trapdoor experiments and pullout tests. Adachi et al. (1985, 1989) proposed a new experimental apparatus that can simulate tunneling by changing the diameter of the tunnel to check the loosening area around the tunnel during excavation. Based on this idea, Kikumoto et al. (2009) carried out improved model tests to investigate the behavior of existing neighboring foundations during tunneling. Figure 8 shows the outline of the experiment apparatus used in this research. The apparatus consisted of 12 bearing blocks which could be displaced in the radial direction 


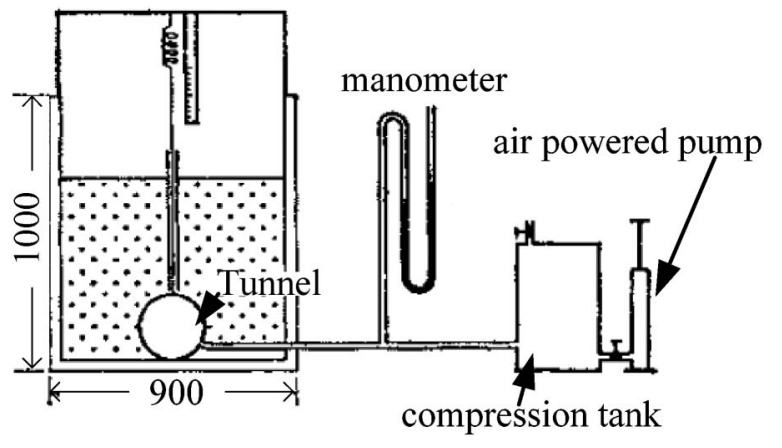

Fig. 9. Earth pressure measuring apparatus for tunnel (Ono and Yamada, 1983)

only. Thus, the looseness due to tunnel excavation was modeled by contracting the tunnel section.

\section{Stress Control}

It is possible to simulate the tunnel excavation process by changing the pressure that acts on the tunnel lining. Ono and Yamada (1983) produced the experimental apparatus shown in Fig. 9 to simulate the tunnel excavation to check the arch effect in sandy ground. The test procedure included first putting a plastic tube with a given inner pressure in the sandy ground, and then lowering the earth pressure to simulate the release of in-situ stress during tunnel excavation. In addition, Sakurai et al. (1994) carried out a series of model tests to investigate loosening pressure of a shallow overburden tunnel using the same method.

\section{ANALYTICAL METHODS}

Numerical analysis is an indispensable tool for tunnel engineers and the majority of the analyses undertaken for design and research of tunnels are now computer based. Due to the development of computers, numerical analyses are widely used to predict surface settlement and tunnel deformation, the influence on neighboring construction and the influence of the ground water. Numerical analyses are also used for the design of tunnel lining and the decision as to which auxiliary methods should be adopted.

A number of numerical analysis methods have been developed in tunnel engineering practice. The methods include the finite element method (FEM), finite difference method (FDM), boundary element method (BEM), and discrete element method (DEM). Unfortunately, there is no unified or standard analysis code or analysis method for the design and research of tunnels. A number of software packages commercially available in tunnel design and analysis are briefly introduced in Table 1 (Choi et al., 2006).

\section{Continuum Analysis}

The continuum analysis methods mainly include FEM, BEM and FDM, and these methods are used extensively for the analysis of underground excavation design prob- lems. The common property of these methods is that the material is idealized as a continuum.

FLAC (Itasca), PLAXIS (PLAXIS B.V) and ABAQUS (SIMULIS) etc. are widely used programs for continuum analyses as shown in Table 1 (Choi et al., 2006). The most commonly used FE analysis code is ABAQUS (SIMULIA, USA) and the most commonly used FD analysis codes are FLAC and FLAC 3D. Examples where both ABAQUS and FLAC have been used are shown in Table 2. Form the table, it can be seen that these continuum analysis codes are widely used to clarify the mechanical behavior of ground during tunnel excavation, the effects of auxiliary methods and the influence of the neighboring constructions. Figure 10 shows an example of the use of FLAC 3D. The benefits of general-purpose software are that it is easy to use and easy to visualize.

There are also many original programs that are widely used for tunnel analyzing by other researchers. Original programs tend to be very effective because they can combine any kind of constitutive model for ground and structures which can simulate the properties of the material pertinently. Cui et al. (2010) carried out a series of 2D FE analysis to check the settlement prevention effect of foot reinforcement side pile, which is a foot reinforcement method. An original FE program named DBLEAVES (Ye et al., 2007) was employed in this study and the subloading $t_{\mathrm{ij}}$ model (Nakai and Hinokio, 2004) was used to simulate the properties of soil. The comparison of the filed data and analytical data in Fig. 11 shows that the analytical results are in good agreement with the measured results.

\section{Discrete Element Analysis}

Soils and rock behave in a rather complicated manner due to their distinct properties. It is sometimes necessary to model the discontinuous behavior of these materials as in the case of soil liquefaction or in simulating the failure and crack of ground and rocks. Therefore, the discrete element method, which is also known as the distinct element method (DEM), was developed to model the materials with separate particles (Cundall, 1971; Cundall and Boar, 1988). This method is suitable not only for the simulation of the behavior of soils but for the behavior of any particulate matter, lincluding powders and grain.

The examples of use of the DEM for tunnel analysis are shown in Table 2 and Fig. 12. The 3D DEM is used for the analyses of a limited domain with large deformation or cracks. On the other hand, for the analysis of large domains, the 2D DEM is employed to simulate the behavior of ground or rock during tunnel excavation. One of the main problems with the DEM is the computational cost of the simulations. In a real case, a large number of particles are required, and the analysis of each contact between them involves a lengthy computational time.

\section{Coupled Method}

The simulation of discontinuities that occur in many geomaterials is difficult using continuum analysis. On the other hand, because DEM requires excessive computa- 
Table 1. Numerical modeling programs used in tunnel design and analysis

\begin{tabular}{|c|c|c|c|}
\hline & Programs & Descriptions & Applications \\
\hline \multirow{6}{*}{ FEM } & $\begin{array}{l}\text { ABAQUS } \\
\text { (SIMULIA, } \\
\text { USA) }\end{array}$ & $\begin{array}{l}\text { For two-dimensional and three-dimensional analysis } \\
\text { Suitable for complicated structural analysis } \\
\text { Attractive for production-level simulations where multiple } \\
\text { fields need to be coupled. }\end{array}$ & $\begin{array}{l}\text { Mechanical behavior of ground and tunnel lining during } \\
\text { tunneling. } \\
\text { Tunnel stability }\end{array}$ \\
\hline & PHASE2 & $\begin{array}{l}\text { Two-dimensional elasto-plastic finite element stress analysis } \\
\text { Well suited for rock engineering } \\
\text { - Automatic finite element mesh generator }\end{array}$ & $\begin{array}{l}\text { Tunneling and excavations in rock } \\
\text { Global overview of engineering solution in rock mass }\end{array}$ \\
\hline & $\begin{array}{l}2 \mathrm{D} \sigma \\
\& \\
3 \mathrm{D} \sigma\end{array}$ & $\begin{array}{l}\text { Two-dimensional and tree-dimensional finite element stress } \\
\text { analysis } \\
\text { High speed analysis } \\
\text { http://www.geolab.jp/index.html (in Japanese) } \\
\text { (Geoscience Research Laboratory Co., Ltd., Japan) }\end{array}$ & $\begin{array}{l}\text { Excavations in soil and rock } \\
\text { Effect of support of tunnel and auxiliary methods } \\
\text { Interaction between ground and structure } \\
\text { Simulating construction process of tunnel and embank- } \\
\text { ment }\end{array}$ \\
\hline & SEEP/W & $\begin{array}{l}\text { A finite element code for analyzing groundwater seepage } \\
\text { and excess pore-water pressure dissipation problems within } \\
\text { porous materials } \\
\text { Available from simple, saturated steady-state problems to } \\
\text { sophisticated, saturated-unsaturated time-dependent prob- } \\
\text { lems } \\
\text { Both saturated and unsaturated flow }\end{array}$ & $\begin{array}{l}\text { Steady state and transient groundwater seepage analysis } \\
\text { for tunnels and excavations } \\
\text { Equivalent properties of the rock mass should be prop- } \\
\text { erly evaluated }\end{array}$ \\
\hline & $\begin{array}{l}\text { Tochnong } \\
\text { professional }\end{array}$ & $\begin{array}{l}\text { Quasi-static and dynamic calculations. } \\
\text { Offering variety of geotechnical and mechanical options. } \\
\text { Mesh independent post-processing by selecting physical } \\
\text { points, lines and surfaces. } \\
\text { (FEAT, Koninkrijk der Nederlanden) }\end{array}$ & $\begin{array}{l}\text { Tunneling and excavations in soil } \\
\text { - Slope stability } \\
\text { \& Pile penetration, horizontal pile testing } \\
\text { (Svoboda and Masin, 2009) }\end{array}$ \\
\hline & Plaxis & $\begin{array}{l}\text { For two-dimensional and three-dimensional analysis } \\
\text { Automatic finite element mesh generator } \\
\text { (PLAXIS B.V., Koninkrijk der Nederlanden) }\end{array}$ & $\begin{array}{l}\text { Tunneling and excavations in soil } \\
\text { Coupling of hydraulic and mechanical behavior } \\
\text { Modeling of hydrostatic and non-hydrostatic pore pres- } \\
\text { sures in the soil } \\
\text { (Di Mariano et al., 2009; Mica et al., 2009) }\end{array}$ \\
\hline \multirow[b]{2}{*}{ DEM } & $\begin{array}{l}\text { PFC 2D } \\
\quad \& \\
\text { PFC 3D } \\
\text { (Itasca) }\end{array}$ & $\begin{array}{l}\text { Discontinue code used in analysis, testing, and research in } \\
\text { any field where the interaction of many discrete objects ex- } \\
\text { hibiting large-strain and fracturing is required. } \\
\text { Not designed to examine a particular type of problem, its } \\
\text { range extends to any analysis that examines the dynamic be- } \\
\text { havior of a particulate system. }\end{array}$ & $\begin{array}{l}\text { Tunneling and excavation in rick or soil. } \\
\text { Seismic analysis } \\
\text { Dynamic fracture analysis for structure, rock and con- } \\
\text { crete. } \\
\text { (Su et al., 2009; Mitarashi et al., 2005) }\end{array}$ \\
\hline & $\begin{array}{l}\text { UDEC } \\
\& \\
3 \mathrm{DEC} \\
\text { (Itasca) }\end{array}$ & $\begin{array}{l}\text { 3DEC is three-dimensional extension of UDEC } \\
\text { Well suited for problems involving jointed rock systems or } \\
\text { assemblages of discrete blocks subjected to quasi-static or } \\
\text { dynamic conditions } \\
\text { Modeling of large deformation along the joint systems } \\
\text { The intact rock (blocks) can be rigid or deformable blocks } \\
\text { Full dynamic capability is available with absorbing bounda- } \\
\text { ries and wave inputs } \\
\text { Joints data can be input by statistically-based joint-set } \\
\text { generator } \\
\text { Coupling of hydraulic and mechanical modeling }\end{array}$ & $\begin{array}{l}\text { Tunneling and excavation in jointed rock mass } \\
\text { Well suited if dominating weak planes are well identified } \\
\text { with their properties properly quantified } \\
\text { Hydrojacking potential analysis for pressure tunnels, } \\
\text { which requires details of joint flow, aperture and dis- } \\
\text { closure relationships } \\
\text { Seismic analysis } \\
\text { Complex three-dimensional behavior of geometry } \\
\text { Suitable for interaction study for crossing tunnels in } \\
\text { jointed rock mass. } \\
\text { (Lunow and Konietzky, 2009) }\end{array}$ \\
\hline
\end{tabular}

tional time, it is not considered practical for use in the simulation of large problems.

The best conceivable analysis method for underground structure is one with no limitations with regard to the analysis area, and one which can simulate the cracks and crush of the soils and rocks as well as the interaction of the soil and structures. As mentioned above, the continuum analysis methods are suitable for all kinds of domains with small deformation, while the discrete element analysis methods are suitable for large deformation. Therefore, an analysis method which combines the continuum analysis and discrete element analysis methods has been developed. The idea is to use the DEM in the subdomain where the fracture occurs, and the FEM can be used in the other part, where the behavior can be represented with a continuum based scheme. 
Table 2. Major Numerical modeling programs used in researches

\begin{tabular}{|c|c|c|c|}
\hline & Subject & Contents & Example \\
\hline \multirow{4}{*}{$\begin{array}{l}\text { ABAQUS } \\
(\text { FEM) }\end{array}$} & \multirow{2}{*}{$\begin{array}{l}\text { Mechanical behavior of } \\
\text { ground during tunnel } \\
\text { excavation. }\end{array}$} & Passive failure of tunnel face in two-layer soil system. & $\begin{array}{l}\text { Wong et al., } \\
2009\end{array}$ \\
\hline & & $\begin{array}{l}\text { Influence of the excavation depth, strength parameters and ground stiffness, } \\
\text { tunnel diameter and geostatic stress ratio on the stability of tunnel face. }\end{array}$ & $\begin{array}{l}\text { Kavvadas et al., } \\
2009\end{array}$ \\
\hline & Auxiliary methods & $\begin{array}{l}\text { Effect of soil nails for tunnel faces stabilizing and the influence of the axial } \\
\text { rigidity EA on face stability. }\end{array}$ & $\mathrm{Ng}$ and Lee, 2002 \\
\hline & Neighboring construction & $\begin{array}{l}\text { Interaction between tunneling and adjacent structures with different tunnel } \\
\text { diameter, width of soil between tunnel crown and building foundation. }\end{array}$ & $\begin{array}{l}\text { Nemati and } \\
\text { Sadaghiani, } 2009\end{array}$ \\
\hline \multirow{3}{*}{$\begin{array}{l}\text { FLAC } \\
\& \\
\text { FLAC 3D } \\
\text { (FDM) }\end{array}$} & Auxiliary methods & $\begin{array}{l}\text { Made a real construction field as a object, which named Abekura, to estimate } \\
\text { the effect of long face bolting which is one of the ground stabilization methods. }\end{array}$ & $\begin{array}{l}\text { Miyanomae et al., } \\
2004\end{array}$ \\
\hline & $\begin{array}{l}\text { Auxiliary methods } \\
\text { Stability of tunnel portals }\end{array}$ & $\begin{array}{l}\text { Investigate the mechanical behavior of tunnel portals and the effect of the face } \\
\text { bolt on stability of tunnel portals during tunnel excavation on soft rock. }\end{array}$ & $\begin{array}{l}\text { Tsuchida et al., } \\
2004\end{array}$ \\
\hline & Simulation method & Simulating complex excavation behavior by numerical analysis. & $\begin{array}{l}\text { Pescara et al., } \\
2009\end{array}$ \\
\hline \multirow{2}{*}{$\begin{array}{l}\text { PFC 2D } \\
\& \\
\text { PFC 3D } \\
\text { (DEM) }\end{array}$} & $\begin{array}{l}\text { Mechanical behavior of the } \\
\text { contact face of pick and rock }\end{array}$ & $\begin{array}{l}\text { A cutting test was carried out by DEM, to exam the cutting forces acting on the } \\
\text { pick during rock cutting. (3D) (Fig. 12) }\end{array}$ & Su et al., 2009 \\
\hline & $\begin{array}{l}\text { Mechanical behavior of } \\
\text { ground during tunnel } \\
\text { excavation }\end{array}$ & $\begin{array}{l}\text { Simulate the excavation of micro tunnel in Torino subsoil to determine the } \\
\text { magnitude of the jacking force needed to advance in to the ground. (2D) }\end{array}$ & $\begin{array}{l}\text { Barla and } \\
\text { Camusso, } 2009\end{array}$ \\
\hline
\end{tabular}

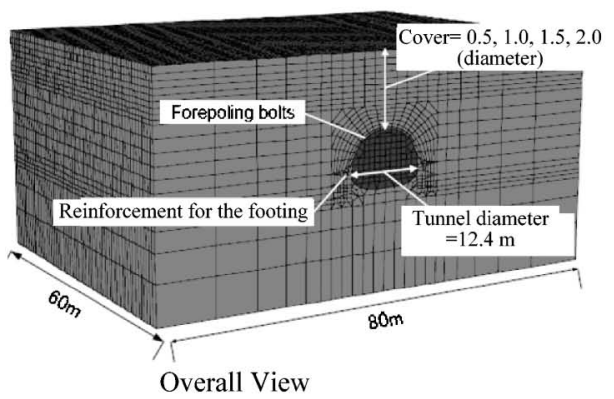

Overall View

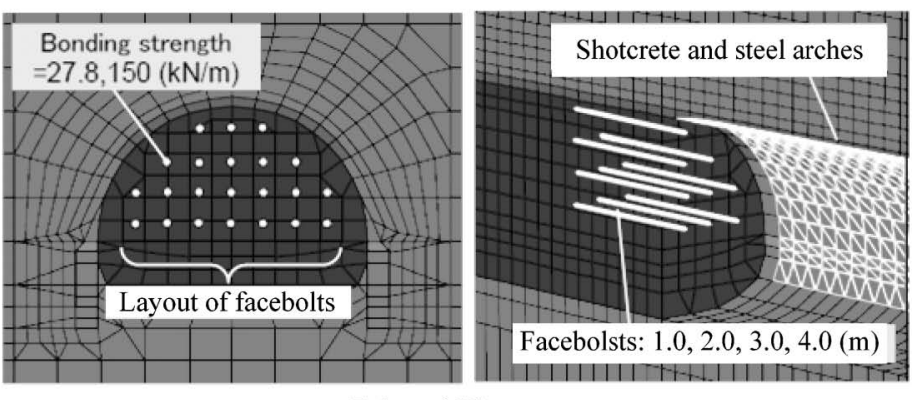

Enlarged View

Fig. 10. Meshes used in DEM program FLAC 3D (Yokota et al., 2009)

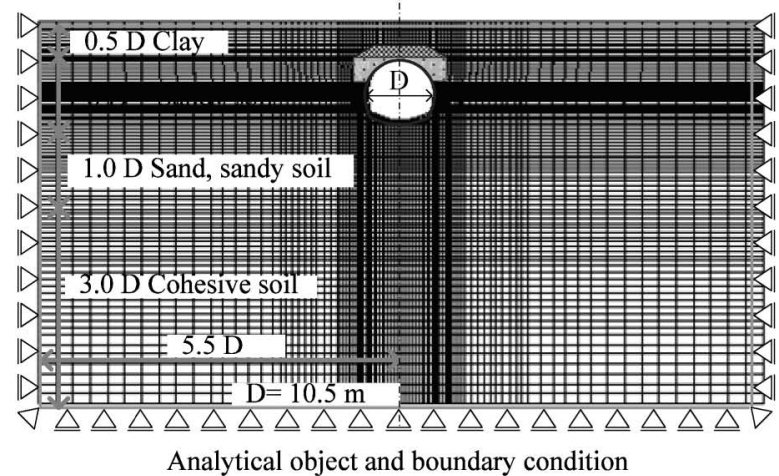

Analytical object and boundary condition

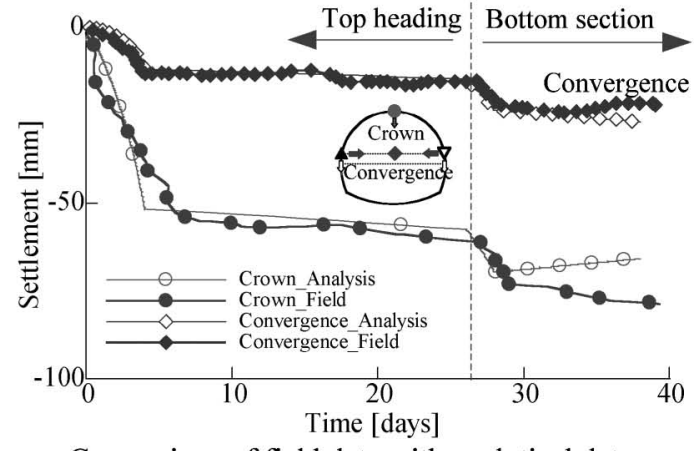

Comparison of field data with analytical data

Fig. 11. Comparison of field data with analytical data (Cui et al., 2010)

Labra et al. (2009) coupled the DEM and FEM to simulate the excavation process using disc cutters. In this research work, a new coupling technique with the FEM was presented, where the DEM was used just in the zone of the rock with damage or fracture and FEM was used in the other parts.

Varo et al. (2009) carried out a calibration study to check the parameters used in the design of the access tun- 

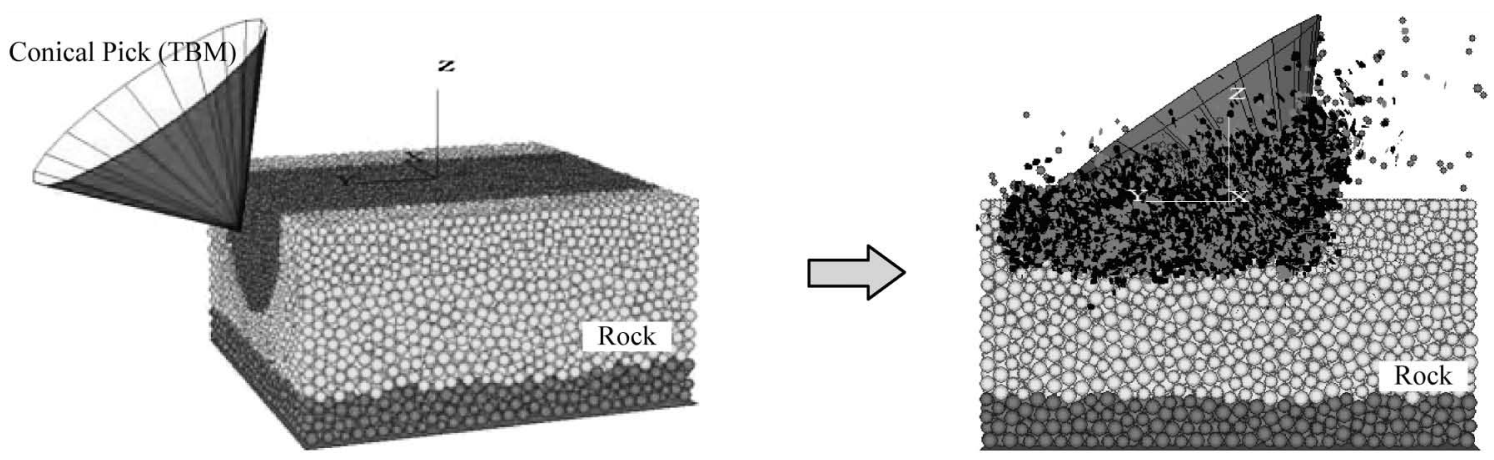

Fig. 12. Schematic view of the specimen and the crack propagation simulated by DEM progam PFC 3D (Su et al., 2009)

nels and to provide information for further design works in the waste repository. In this research work, DEM was used for modeling the jointed rocks, which are the discontinuous media, by representing them as an assemblage of discrete blocks. Each block was treated as rigid or deformable material of finite-difference elements, while the discontinuities governed the boundary conditions between the blocks.

\section{CONCLUSIONS}

This paper has introduced the present state of the model tests and the numerical analysis methods for the tunnel excavation problem. Either the model tests or the numerical analysis is indispensable for clarifying the mechanical behavior of ground and tunnel during tunnel excavation, the effects of the auxiliary methods and the influence of existing neighboring structures, for example. As has been explained in this overview, numerous experimental methods and analysis codes have been developed for the design and research of tunnels, both in Japan and overseas.

However, the studying methods used in the papers published in S\&F are few. The trapdoor apparatus was used in $50 \%$ of the model experiments and FEM was adopted in $80 \%$ of the analysis works. In addition, most of the researchers in Japan preferred to develop original programs. The principal factor responsible for above phenomena is the small number of tunnel related papers published in S\&F. The vibrant submission of tunnel related papers is strongly encouraged.

The future projection is that the construction of tunnels will continue to increase, and the problems related to prediction, monitoring and the evaluation of the tunnel and the ground will remain. Model tests and numerical analysis will no doubt become increasingly more important. At this point in time, it would appear that the the optimum approach to tunnel related studies will involve a good combination of the numerical analysis and experimental methods.

\section{REFERENCES}

1) Adachi, T., Tamura, T., Yashima, A. and Ueno, H. (1985): Behav- ior of and simulation of sandy ground tunnel, Journal of Geotechnical Engineering, JSCE, (358/III-3), 129-136 (in Japanese).

2) Adachi, T., Kimura, M., Yamaguchi, N. and Osada, H. (1989): Behavior of tunnels in sandy ground, Annuals, Disas. Prev. Res. Inst. Kyoto Univ., (32/B-2), 183-192 (in Japanese).

3) Adachi, T., Kimura, M., Tamura, T. and Aramaki, S. (1994): Experimental and analytical studies of earth pressure, Proc. 8th Int. Conf. on Computer Methods and Advances in Ggeomechanics, 2417-2422.

4) Barla, M. and Camusso, M. (2009): Modelling microtunnel excavation in Torino by particle elements, 2nd Int. Conf. on Computational Methods in Tunnelling, EURO TUN 2009, 207214.

5) Choi, S. (2006): Computations in tunneling: A revisit to numerical modeling programs, PB Network, Issue 62, 59-61.

6) Christian, J. T. and Wong, I. H. (1973): Errors in simulating excavation in elastic media by finite elements, Soils and Foundations, 13(1), 1-10.

7) Cui, Y., Kishida, K. and Kimura, M. (2008): Experimental study on effect of auxiliary methods for simultaneous settlement at subsurface and surface during shallow overburden tunnel excavation, Japanese Geotechnical Journal, 3(3), 261-272.

8) Cui, Y., Kishida, K. and Kimura, M. (2010): Analytical study on the control of ground subsidence arising from the phenomenon of accompanied settlement using foot reinforcement side pile, Deep and Underground Excavation, ASCE Geotechnical Special Publication, 307-312.

9) Cundall, P. A. (1971): A computer model for simulating progressive, large-scale movements in blocky rock system, Proc. Int. Symp. for ISRM, Nancy, Paper No. II-8.

10) Cundall, P. A. and Boar, M. (1988): A microcomputer program for modeling large-strain plasticity problems, Proc. 6th Int. Conf. on Numerical Methods in Geomechanics, Innsbruck, Austria, 2101-2108.

11) Di Mariano, A., Persio, R., Gens, A., Castellanza, R. and Arroyo, M. (2009): Influence of some EPB operation parameters on ground movements, 2nd Int. Conf. on Computational Methods in Tunnelling, EURO TUN 2009, 43-50.

12) Dufour, N., Leo, C. J., Deleruyelle, F. and Wong, H. (2009): Hydromechanical responses of a decommissioned backfilled tunnel drilled into a poro-viscoelastic medium, Soils and Foundations, 49(4), 495-507.

13) Goto, S., Burland, B. J. and Tatsuoka, F. (1999): Nonlinear soil model with various strain levels and its application to axisymmetric excavation problem, Soils and Foundations, 39(4), 111-119.

14) Hashimoto, T., Nagaya, J. and Konda, T. (1999): Prediction of ground deformation due to shield excavation in clayey soils, Soils and Foundations, 39(3), 53-61.

15) Kavvadas, M., Prountzopoulos, G. and Tzivakos, K. (2009): Prediction of face stability in unsupported tunnels using 3D finite element analysis, 2nd International Conference on Computational Methods in Tunnelling, EURO TUN 2009, 825-832. 
16) Khoshnoudian, F. and Shahrour I. (2002): Numerical analysis of the seismic behavior of tunnels constructed in liquefiable soils, Soils and Foundations, 42(6), 1-8.

17) Kikumoto, M., Shahin, H. M., Nakai, T., Nagata, M. and Toda, K. (2009): 54th Geotechnical Engineering Symposium, 355-362 (in Japanese).

18) Kirsch, A. (2009): Experimental and numerical investigation of the face stability of shallow tunnels in sand, Acta Geotechinica, 5(1), 43-62.

19) Kitagawa, T., Goto, M., Isogai, A., Yashiro, K. and Matsunaga, T. (2005): Analysis on behavior of soft ground tunnels with low earth covering, Proc. Tunnel Engineering, JSCE, 15, 203-210 (in Japanese).

20) Komiya, K., Soga, K., Akagi, H., Hagiwara, T. and Bolton, M. D. (1999): Finite element modeling of excavation and advancement processes of a shield tunneling achine, Soils and Foundations, 39(3), 37-52.

21) Labra, C., Rojek, J. and Onate, E. (2009): Discrete element method simulation of the excavation process using disc cutters, 2nd Int. Conf. on Computational Methods in Tunnelling, EURO TUN 2009, 177-182.

22) Lee, K. M., Ji, H. W., Shen, C. K., Liu, J. H. and Bai, T. H. (1999): Ground response to the construction of Shanghai metro tunnel-line 2, Soils and Foundations, 39(3), 113-134.

23) Lee, S. W., Bolton, M. D., Mair, R. J., Soga, K. and Hagiwara, T. (2002): Modeling of sequential injections near tunnel linings, Soils and Foundations, 42(6), 9-22.

24) Longanthan, N., Poulos, H. G. and Xu, K. J. (2001): Ground and pile-group responses due to tunnelling, Soils and Foundations, 41(1), 57-67.

25) Lunow, C. and Konietzky, H. (2009): Two dimensional simulation of the pressing and the cutting rock destruction, 2nd Int Conf. on Computational Methods in Tunnelling, EURO TUN 2009, 223-230.

26) Mica, L., Racansky, V. and Krasny, O. (2009): Analysis of interaction of retaining walls with underground structures in clay, 2nd Int. Conf. on Computational Methods in Tunnelling, EURO TUN 2009, 233-240.

27) Mitarashi, Y., Tezuza, H., Toru, H., Okabe, T. and Jiang, Y. (2005): The evaluation of the effect of long face bolting by 3D distinct element method, Proc. Tunnel Engineering, JSCE, 15, 77-82 (in Japanese).

28) Miyanomae, S., Morita, A., Matsui, M., Sakai, T. and Nashimoto, Y. (2004): Study on the effects of ground stabilization methods for unstable ground excavation, Proc. Tunnel Engineering, JSCE, 14, $107-114$ (in Japanese).

29) Murayama, S. and Matsuoka, H. (1971): Earth pressure on tunnels in sandy ground, Journal of Geotechnical Engineering, JSCE, 187, 85-108 (in Japanese).

30) Nakai, T., Xu, L. M. and Yamazaki, H. (1997): 3D and 2D model tests and numerical analyses of settlements and earth pressures due to tunnel excavation, Soils and Foundations, 37(3), 31-42.

31) Nakai, T. and Hinokio, M. (2004): A simple elastoplastic model for normally and over consolidated soils with unified material parameters, Soils and Foundations, 44(2), 53-70.

32) Nemati, M. R. and Sadaghiani, M. H. (2009): Interaction between tunnel and adjacent structures using a two-dimensional finite element analysis, 2nd Int. Conf. on Computational Methods in Tunnelling, EURO TUN 2009, 961-968.

33) $\mathrm{Ng}, \mathrm{C}$. W. W. and Lee, G. T. K. (2002): A three dimensional parametric study of the use of soil nails for stabilizing tunnel faces, Computers and Geotechnics, 29, 673-697.

34) Ono, K. and Yamada, M. (1983): Study on the arch action above the tunnel driven in the cohesionless sand, Journal of Geotechnical Engineering, JSCE, (339), 137-146 (in Japanese).

35) Pescara, M., Floria, V. and Repetto, L. (2009): Simulating complex excavation behavior by numerical analysis, 2 nd Int. Conf. on Computational Methods in Tunnelling, EURO TUN 2009, 833-840.

36) Sato, K. (1983): Hydraulic character of discharge hydrograph for tunneling, Soils and Foundations, 23(4).

37) Sakurai, S., Kawashima, I., Kawabata, Y. and Saragai, A. (1994): Model tests on deformation and loosening pressure of shallow tunnel, Journal of Geotechnical Engineering, JSCE, (487/III-26), 271-274 (in Japanese).

38) Seo, K., Domon, T. and Nishimura, K. (2005): Evaluation on the effect of face bolts, Proc. Tunnel Engineering, JSCE, 15, 83-88 (in Japanese).

39) Shahin, H. M., Nakai, T., Hinokio, M. and Yamaguchi, D. (2004): $3 \mathrm{D}$ effects on earth pressure and displacements during tunnel excavations, Soils and Foundations, 44(5), 37-49.

40) Shiraishi, S. (1969): Recent major shield-driven tunnels through soft ground in Japan, Soils and Foundations, 9(3), 16-34.

41) Su, O., Akcin, N. A. and te Kamp, L. (2009): Modeling of cutting forces acting on a conical pick, 2nd Int. Conf. on Computational Methods in Tunnelling, EURO TUN 2009, 199-206.

42) Sugiyama, T., Hagiwara, T., Nomoto, T., Nomoto, M., Ano, Y., Mair, R. J., Bolton, M. D. and Soga, K. (1999): Observations of ground movement during tunnel construction by slurry shield method at the docklands light railway Lewisham extension-east London, Soils and Foundations, 39(3), 99-112.

43) Sung, E. S., Shahin, H. M., Nakai, T., Hinokio, M. and Yamamoto, M. (2006): Ground behavior due to tunnel excavation with existing foundation, Soils and Foundations, 46(2), 189-207.

44) Svoboda, T. and Masin, D. (2009): Optimisation of parameters for simulating a NATM tunnel in stiff clays based on a 3D model of exploratory adit, 2nd Int. Conf. on Computational Methods in Tunnelling, EURO TUN 2009, 249-256.

45) Taguchi, Y., Hada, M. and Kagawa, K. (2003): Full-sized test on the reinforcing effect of the pre-lining with the reverse $\mathrm{T}$ type body, Proc. Tunnel Engineering, JSCE, 3, 149-154 (in Japanese).

46) Terzaghi, K. (1936): Stress distribution in dry and saturated sand above a yielding trap-door, Ist Int. Conf. on S.M.F.E., 307-311.

47) Terzaghi, K. (1943): Theoretial Soil Mechanics, John Wiley \& Sons, New York.

48) Tsuchida, J., Maeda, T., Asakawa, T., Takeuchi, H. and Uchida, T. (2004): Construction of rock tunnel portal in soft and altered zone, Proc. Tunnel Engineering, JSCE, 14, 189-194 (in Japanese).

49) Varo, A., Megyeri, T. and Loson, A. (2009): Back-analysis of access tunnels for the Bataapati nuclear repository, Hungary, Proceedings of ITA-AITES World Tunnel Congress 2009 and the 35th ITA-AITES General Assembly, P-08-08.

50) Wong, K. S., Ng, C. W. W., Chen, Y. M. and Bian, X. C. (2009): Three-dimensional analysis of passive failure of circular tunnel face in layered ground, 2nd Int. Conf. Computational Methods in Tunnelling, EURO TUN 2009 841-848.

51) Ye, B., Ye, G. L., Zhang, F. and Yashima, A. (2007): Experiment and numerical simulation of repeated liquefaction-consolidation of sand, Soils and Foundations, 47(3), 547-558.

52) Yokota, Y., Lee, J. W., Date, K. and Yamamoto, T. (2009): Numerical approach for simple estimation of reinforcing effects of facebolts, Hungary, Proceedings of ITA-AITES World Tunnel Congress 2009 and the 35th ITA-AITES General Assembly, O-09-09.

53) Yoshikoshi, W., Watanabe, O. and Takagi, N. (1978): Prediction of ground settlements associated with shield tunneling, Soils and Foundations, 18(4), 47-59. 